\title{
User experiences with decentralised water systems in an ecological residential area
}

\author{
A. A. E. Luising \\ Delft University of Technology, Faculty of Architecture, \\ Environmental Design, The Netherlands
}

\begin{abstract}
EVA-Lanxmeer is an ecological residential area in the centre of The Netherlands. An integrated (waste) water concept was an essential part of the design. On the incoming side two water streams are distinguished: drinking water and household water. On the outgoing side the household wastewater is divided into two streams: black water and grey water. This paper discusses the attitude of the users on water saving and water treatment systems. The central theme is the relation between the physical implementation of the water systems in the design and the use of it by the inhabitants of the area. For this research interviews were held with the inhabitants of the project. The water concept was an important part of the concept of the project and it added to the visible quality of the area. Furthermore, the people considered the systems very reliable even if the systems had not yet been put into practice.

Keywords: grey water, black water, wastewater, decentralised sanitation, user experiences, ecological residential area.
\end{abstract}

\section{Introduction}

Central end of pipe wastewater management causes various environmental and social problems. Integrated water management can offer an opportunity for residential areas to improve building and living quality.

Centralised wastewater concepts are not sustainable: they use water for flushing, need for infrastructure, loss of valuable nutrients in the wastewater and a lack of user consciousness. Decentralised wastewater concepts can be a solution for these problems. The change from central to decentralised systems means that wastewater systems come closer or even in the built environment. 
This causes a new view on the subject. How are these systems to be integrated in the built environment? Which new challenges are to be met? What function do these systems have except for cleaning wastewater. How have they to be used and maintained.

This paper describes a research about the implementation of decentralized systems and user aspects. Lanxmeer, an ecological area in Culemborg, was used as a case study. In this area an integrated water system was part of the design. Some parts of the system were functioning at the time of the research; some parts just existed on drawings.

Goal of the research was to find relations between user aspects and the physical implementation of the system. For a successful application of a decentralized system a good technical design is essential. But after building the system the user and maintenance phase are just as important for success. Aspects as trust, responsibility, information, physical appearance and location play an important role.

\subsection{Location}

EVA-Lanxmeer is located in Culemborg in the centre of the Netherlands. The project is realized in cooperation with future inhabitants.

Goal was to create an integrated design in which sustainable development and a high quality of the living environment played a central role.

The houses and buildings lay horseshoe shaped round a water collection area and consist of three neighbourhoods, fig. 1. The area is characterised by a spacious and green lay-out.

The program consists of two hundred houses, office space, a city farm and a multifunctional congress and educational centre. Except for attention for renewable materials and an energy neutral concept an integrated water system was implemented $[1,2]$.

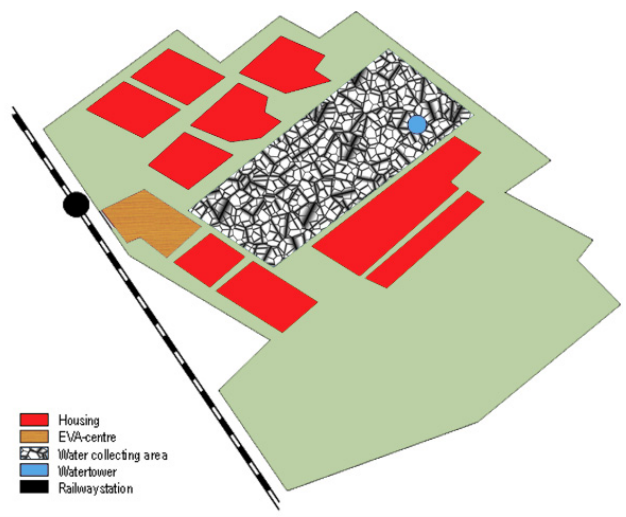

Figure 1: $\quad$ Location of Lanxmeer. 


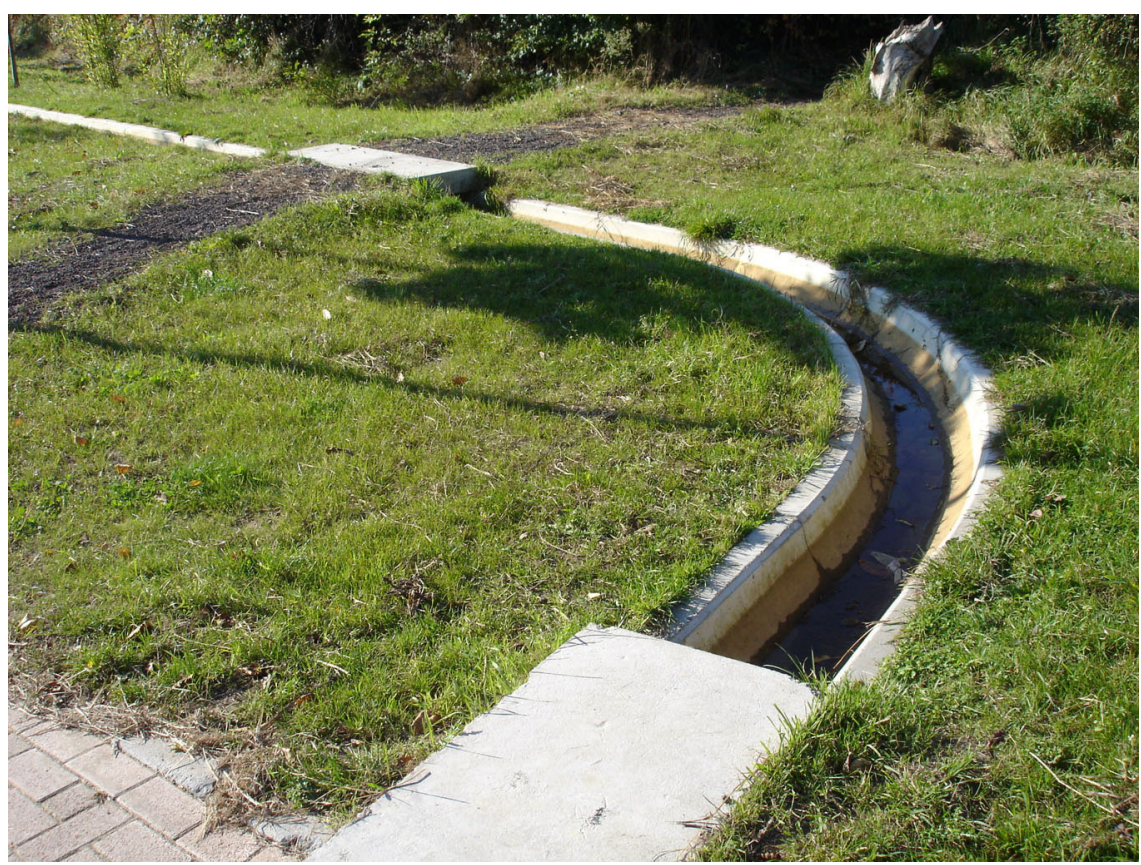

Figure 2: $\quad$ Water made visible in Lanxmeer: open rain water gutters.

\subsection{Process and organisation}

Lanxmeer was founded in 1996 by a project team formed by the municipality of Culemborg and the EVA-Foundation. In 1998 the inhabitant's organisation BEL was founded. It looks after the interests of the inhabitants. It consists of various working groups, for example traffic, gardens and car sharing. The project office is responsible for the organisation of the building project and informs the inhabitants of Lanxmeer about the progress.

\subsection{Water system}

The plan location in the middle of a water collection area was the basic principle for the urban design. The water systems take a very prominent role in the area. The water systems take considerable space on prominent positions. Water is visible everywhere in Lanxmeer, fig. 2. Because the area is situated in a water collection area this made special demands on the building manner related to the water system. At the same time this offered opportunities to show many aspects of sustainable water management. The houses are built on a foam concrete foundation in stead of building on piles to prevent contact between drinking water layers in the soil with contaminated water layers. The water collection area is protected from dirty water inlet by creating a constant overpressure in the area. The wastewater flows away from the water collection area. 


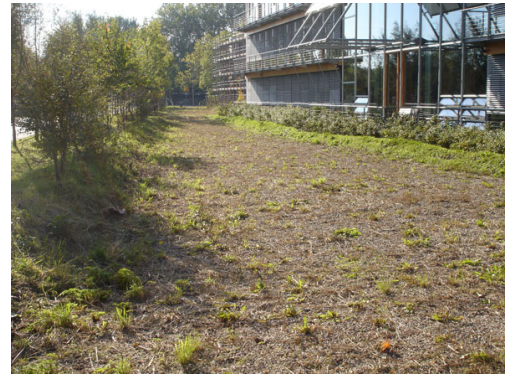

Figure 3: $\quad$ Reed bed filter.

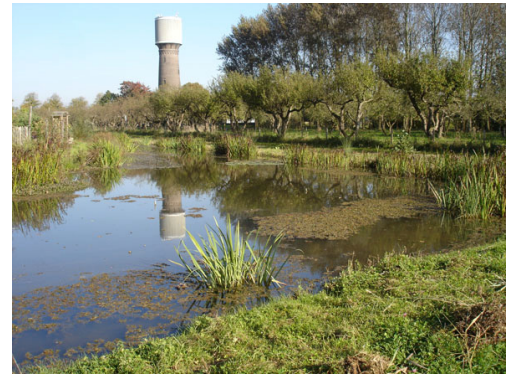

Figure 4: Rainwater collecting pond.

The basic principle was to save and reuse as much water as possible and protect the vulnerable water collection area. Every of the three neighbourhoods have their own water system for grey, black (toilet water) and rainwater. Rainwater is collected in retention ponds situated around the water collection area, fig. 4.

The grey water is treated in one of the three reed bed filters, fig. 3. The effluent infiltrates in wadi's. These wadi's are used as well to infiltrate a part of the rainwater. The retention ponds for collecting the rainwater are situated around the water collecting area. The black water is collected from the whole area and in the future it will be treated in a biogas treatment plant. At this moment it flows to the sewer which was added as a back up system in the design.

Part of the plan is a multifunctional conference and education centre.

The wastewater of this centre will be treated separately in a Living Machine.

\section{Methods}

In order to investigate the relation between implementation and the user aspects of the water systems, a research frame was set up.

Firstly the water systems in the area were studied. This included the technical specifications, the implementation in the design of the area and the process from design to implementation and use of the water systems.

Inhabitants of the area where interviewed about their attitude to decentralised water systems and their experiences so far. A list of questions was set up using key themes from the system analysis and former inhabitant research. 102 letters were sent to all the inhabitants of EVA-Lanxmeer. Fifteen in depth interviews were held. Because of the small number of interviews the results are just interpreted qualitatively.

The interviews consisted of five parts:

- Common questions about the residential area

- Decision-making, participation and process: the commitment and opinion of the respondents regarding the water system was checked

- The wastewater treatment system: knowledge and point of view was tested. 
- Maintenance

- Application: these questions go in to the practical use of the systems and final products.

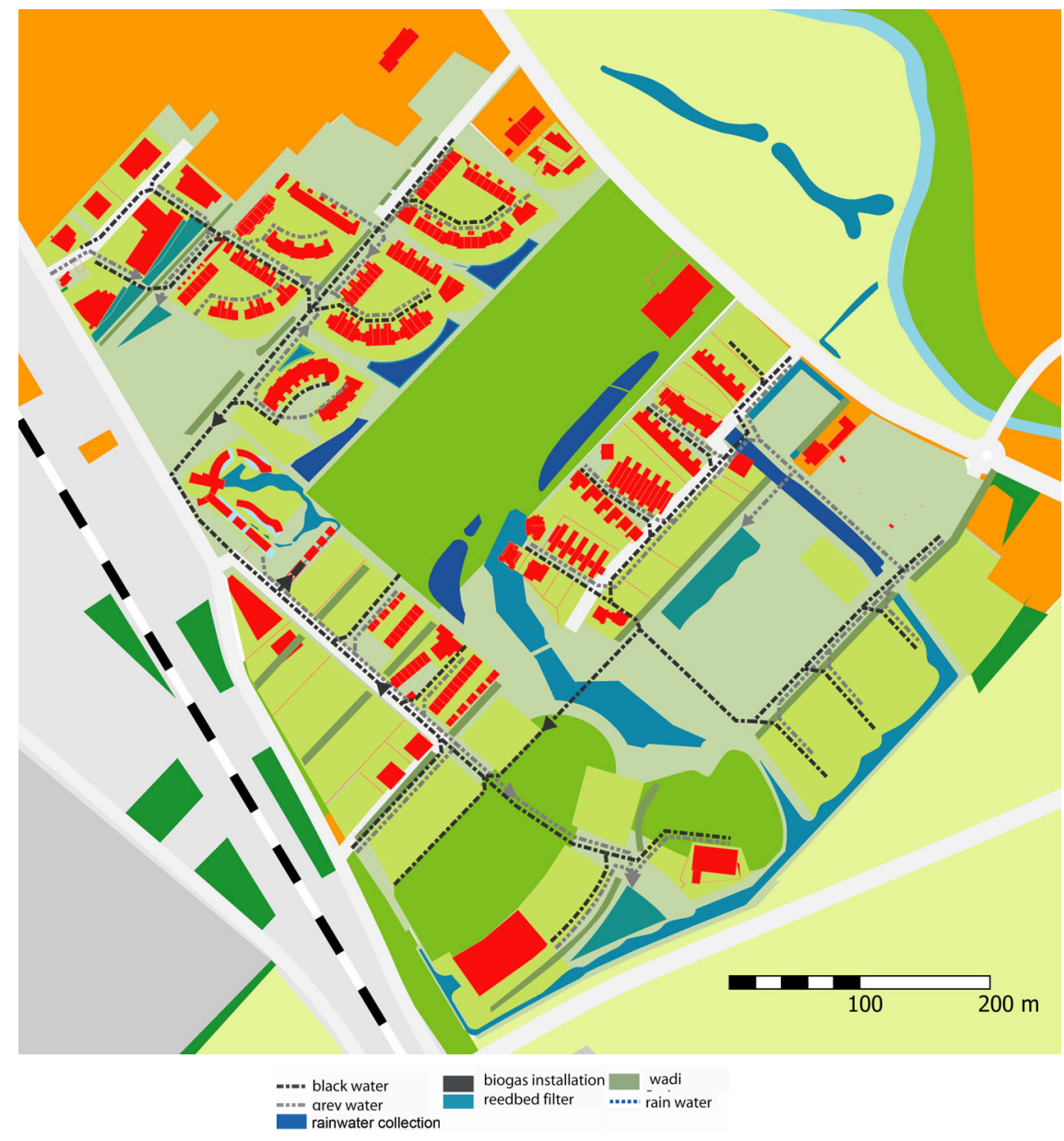

Figure 5: Wastewater systems in Lanxmeer, picture Paul de Graaf.

\section{Results and discussion}

\subsection{Trust}

Most respondents trusted the project office to take the right decisions regarding the water system. When they were asked if any health risks were involved with the system, nobody expected any problems. They even planned to use the future compost of the anaerobic digester in the communal gardens. Although many of 
the respondents were not satisfied with the information they received during the process, this did not lead to a decreased level of trust in the water system itself. For a functioning grey water system it is important that users do not contaminate the reed beds by disposing toxic materials in the kitchen sink. For example no chlorine or remains of paint can be disposed. There was some distrust between inhabitants; they were afraid that others would not treat the grey water system with care. The residents are responsible for the water system together and therefore dependant on each other's behaviour.

\subsection{Information}

Inhabitants are informed about the water system by the project office of Lanxmeer. Information about the household water is the responsibility of the supplier of the household water. Respondents wanted to be informed about the water systems by meetings and mail.

During the interviews it was not clear if the household water network would be brought into use. The information provision by the supplier of the water was considered poor. None of the respondents was informed about this process. Due to a governmental regulation it was prohibited to use household water in houses.

\subsection{Identity}

There seems to be a separation between inhabitants of the various neighbourhoods. The difference between owner-occupied houses and rented houses is not clearly present although some house-owners show their concern about tenants not visiting information meetings. This could cause problems when they have to be informed about using the water system. Inhabitants who not considered themselves as environmental friendly were influenced by their neighbours; good examples were taken over. In general the respondents believed that the water system is an integrated part of Lanxmeer. In spite of the fact that a considerable part of the system was not yet brought into use (no household water and black water system) they would be very disappointed if this was not going to happen.

The water system is considered as one of the essential projects in the area.

The area would have failed if the decentralized water system would not be completed according to most of the respondents. Previous research [3, 4] showed that most of the inhabitants moved to Lanxmeer because of the ecologically sound character. Besides, the water system has important social control function. The sensitivity from the grey water system means that users have to treat it with care. If the grey water system would not be put into use there would be no necessity to use ecologically sound products and with it the solidarity would decrease

\subsection{Location of the water system}

At the time of the interview the grey water system was constructed. The motives of the designers to locate the system on a certain place diverged. 
The location involved accessibility, safety and educational reasons. One the one hand the water system is an important visiting card of the area. For this reason it should be visible to as many people as possible. For example places on the border along a busy cycle track where many people pass on their way to the Station, fig. 6. On the other hand the water system is vulnerable and the system could be better situated in a sheltered place.

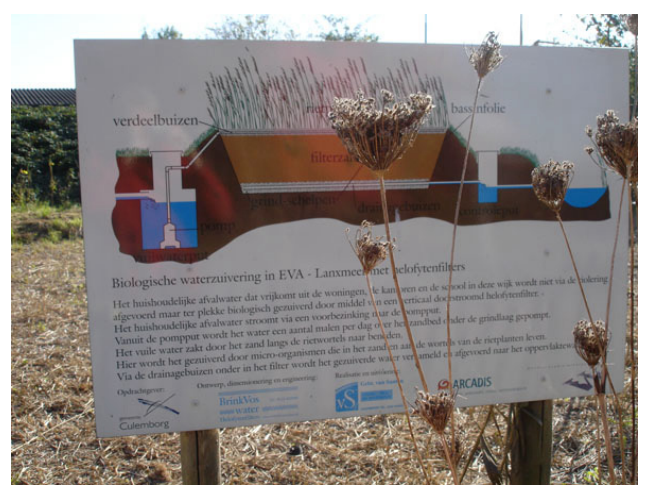

Figure 6: Information board reed bed filter along cycling track.

\subsection{Maintenance}

Most respondents do not want to be involved in the maintenance of the water system. It takes too much time and many of them already are a member of other teams. Some of the respondents doubt if they have enough knowledge of the water system.

\subsection{Scale}

The level of social cohesion is highest on the smallest level of scale in Lanxmeer: the courts. Inhabitants are responsible together for the system, use and maintenance. Therefore the optimum level of scale for the water system would be the court level, fig. 7. This would involve the users more in the system, although respondents indicated that they did not consider themselves qualified for maintenance tasks. Furthermore the infrastructure can be more efficient. The recycled water could be used in de court as well.

\subsection{Selection of water system}

Saving water is the main motive for inhabitants to have a decentralised water system. Saving costs is not an issue. Respondents expect that using a decentralised water system will improve the (environmental) quality of their living environment. In selecting a water treatment system a number of aspects are of concern for inhabitants. To what extent the system can be integrated in 


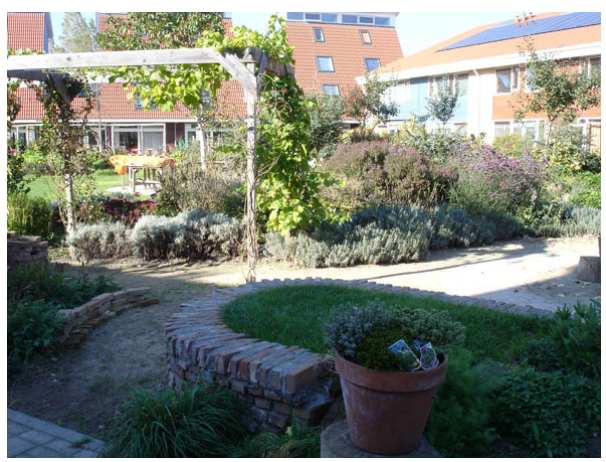

Figure 7: Communal garden in court.

the situation is of importance. Respondents choose for a system that merges in its surroundings. A helophyte filter is a good example of a merging system because the plant fit well in the green design. However, because Lanxmeer aims to be a model for a sustainable area in which sustainable techniques are shown, systems are made visible in the area. Rainwater flow through open gutters to the retention ponds and in de future educational centre a Living Machine is planned.

\section{References}

[1] Website inhabitants EVA-Lanxmeer (BEL), www.bel-lanxmeer.nl.

[2] Website EVA-Lanxmeer Foundation, www. eva-lanxmeer.nl.

[3] V\&L Consultants, Bewonerservaringen EVALanxmeer te Culemborg, Rotterdam, 2003.

[4] Ger de Vries, Bewoners in EVA-Lanxmeer. Dik tevreden, Magazine Puur Bouwen, nr. 5, 2004. 